INT. J. REMOTE SENSING, 2001, VOL. 22, NO. 11, 2171-2191

\title{
Characterizing land surface anisotropy from AVHRR data at a global scale using high performance computing
}

\author{
S. N. V. KALLURI†*, Z. ZHANG , J. JÁJÁ§, S. LIANG † and \\ J. R. G. TOWNSHEND\| \\ $\dagger$ Department of Geography, University of Maryland at College Park, \\ Maryland 20742, USA \\ ¥Institute for Advanced Computer Studies and Dept. of Electrical Engineering, \\ University of Maryland at College Park, Maryland 20742, USA \\ §Institute for Advanced Computer Studies, University of Maryland at College \\ Park, Maryland 20742, USA \\ | Department of Geography and Institute for Advanced Computer Studies, \\ University of Maryland at College Park, Maryland 20742, USA
}

\section{(Received 14 August 1998; in final form 20 December 1999)}

\begin{abstract}
We used the multi-temporal ten-day composite data from the Advanced Very High Resolution Radiometer (AVHRR) for the years 1983 to 1986 to retrieve the Bidirectional Reflectance Distribution Function (BRDF) using high performance computing techniques. Three different models are used: a simple linear model, a semi-empirical iterative model and a temporal model. The objectives of this study were to compare the performance of different BRDF models at a global scale, assess the computational requirements and optimize the algorithm implementation using high performance computational techniques, and to determine if there is any coherent spatial structure in the coefficients of different BRDF models corresponding to different land cover types. The standard error between model computed reflectances and the input data was used to quantify the performance of the models. Even though the iterative model is computationally more expensive (158 minutes) than either the simple linear model (15 minutes) or the temporal model (16 minutes), the results from all the three models were very similar when the BRDF was estimated at discrete time periods. If the BRDF models were applied without dividing the input data into discrete time intervals, then the temporal model gave better results than the other two. All the models were run on an IBM SP2 parallel machine with 16 CPUs. Most of the mountainous and snow covered areas in high latitudes had null values since the cloud screening algorithm used in the Pathfinder processing performed poorly in distinguishing between snow and clouds. The BRDF coefficients of the iterative model and the Fourier coefficients of the temporal model showed a strong spatial structure corresponding to known variations in land cover.
\end{abstract}

\section{Introduction}

Since much of the land surfaces is anisotropic, it is important to understand the dependency of land surface reflectance measurements on the illumination and observation geometry in remote sensing studies. Angular variations in surface

*Current address: Raytheon, 1616 McCormick Drive, Upper Marlboro, MD 20774, USA.

International Journal of Remote Sensing

ISSN 0143-1161 print/ISSN 1366-5901 online (C) 2001 Taylor \& Francis Ltd http://www.tandf.co.uk/journals 
reflectance are generally described by the Bidirectional Reflectance Distribution Function (BRDF) (Nicodemus et al. 1977):

$$
f_{\mathrm{r}}\left(\theta_{\mathrm{s}}, \varphi_{\mathrm{s}} ; \theta_{\mathrm{v}}, \varphi_{\mathrm{v}} ; \lambda\right)=\frac{\mathrm{d} L\left(\theta_{\mathrm{s}}, \varphi_{\mathrm{s}} ; \theta_{\mathrm{v}}, \varphi_{\mathrm{v}} ; \lambda\right)}{\mathrm{d} E\left(\theta_{\mathrm{s}}, \varphi_{\mathrm{s}} ; \lambda\right)}
$$

where $f_{\mathrm{r}}$ is the BRDF $\left(\mathrm{sr}^{-1}\right), \mathrm{d} L$ is the reflected radiation for an incident beam of intensity $\mathrm{d} E$ at wavelength $\lambda, \theta$ and $\varphi$ are the zenith and azimuth angles respectively and the subscripts $s$ and $v$ denote the angles of the Sun and view directions respectively. The BRDF is often described by the bi-directional reflectance factor, $\rho=f_{\mathrm{r}} \pi$.

Surface BRDF variations can cause significant variations in multi-temporal measurements that are made at different illumination and view angles, especially from a wide field-of-view instrument such as the Advanced Very High Resolution Radiometer (AVHRR) (Holben 1986, Goward et al. 1991, Gutman 1991, Cihlar et al. 1994, Burgess and Pairman 1997, Li et al. 1996). Thus, for most remote sensing applications, it is desirable to accurately characterize surface BRDF and normalize the measurements to a consistent geometry. Furthermore, the surface BRDF has the potential to provide important information about the state variables such as the leaf area index (LAI) (Myneni et al. 1995). Knowledge of surface BRDF is also important when deriving surface albedo, which is an important variable in energy balance and radiative transfer modelling (see e.g. Pinker and Laszlo 1990). Since our current knowledge of the BRDF is limited, Earth Observing System (EOS) sensors such as the Multi-angle Imaging Spectroradiometer (MISR) have been specifically designed to provide us with multiangluar measurements, so that we can better understand the BRDF over different land cover types at a global scale.

Current models to retrieve BRDFs can be categorized as empirical (e.g. Walthall et al. 1985), semi-empirical (e.g. Rahman et al. 1993b) or physically based models (e.g. Myneni et al. 1992). The empirical models derive a set of statistical coefficients by fitting a polynomial function to observed reflectances at different geometries. Since the coefficients are derived statistically, they have little direct physical meaning. A number of surface parameters (such as the size, shape, and distribution of vegetation canopy elements) are used to describe the shape of the BRDF in physical models. From a set of observations, the parameters are derived by inverting the physical model. The physical model is initialized using guesses of the values of the parameters, and the model is iterated until the computed reflectances best fit the observed data. A merit function, such as a least-squares difference between the modelled values of the reflectance and the observed data, is used to determine the accuracy of the fit. Thus, the physical models can be used to derive surface variables such as the LAI, which can then be used to estimate other parameters that are important in modelling biogeochemical cycles, such as surface roughness or fraction of photosynthetically absorbed radiation. However, the physical models are computationally expensive and the number of parameters required can be large. The accuracy of the derived parameters depends upon the accuracy of the input data, and the robustness of the model inversion. Semi-empirical models (e.g. Roujean et al. 1992, Rahman et al. $1993 a, b)$ have a set of statistically derived coefficients with physical meaning. Compared with the physical models, fewer parameters are required and these models are thus relatively easy to implement.

Reflectance measurements from EOS sensors such as the Moderate Resolution Imaging Spectroradiometer (MODIS) and MISR are expected to provide the 
capability to retrieve surface BRDF operationally through a combination of well tested algorithms (Diner et al. 1996, Strahler et al. 1999). However, these algorithms have not been previously applied at a global scale and there remain several issues that need to be addressed:

- How do these algorithms perform at a global scale?

- What are the computational requirements and how do we optimize the computational performance?

- Is there a spatial structure in the model coefficients corresponding to different land cover types?

Our objective is to answer these questions by applying some of the BRDF algorithms chosen for MODIS and MISR to global AVHRR data.

Several studies aimed at deriving BRDF from AVHRR data have been reported in the literature (e.g. Cihlar et al. 1994, Braswell et al. 1996, Privette et al. 1996). However, these studies used samples of pixels from imagery at varying spatial and temporal resolutions and application of these algorithms at a global scale has never been performed. We have implemented three BRDF algorithms in this study using the Pathfinder AVHRR Land (PAL) dataset (James and Kalluri 1994). From the suite of BRDF algorithms proposed for implementation for MODIS and MISR instruments, we chose the modified Walthall model (Walthall et al. 1985, Nilson and Kuusk 1989) and the Coupled Surface Atmosphere Reflectance (CSAR) model (Rahman et al. 1993a, b) for deriving the BRDF from AVHRR data. We believe that these two algorithms are good candidates for addressing the above mentioned issues, since they have been shown to work well over different cover types (e.g. Rahman et al. 1993a, Lewis et al. 1995, Russell et al. 1995, Diner et al. 1996, O'Neill et al. 1997). Besides these two models, we also used the temporal model of Liang and Townshend (1997), which uses an additional temporal function besides the geometry of observations to describe the BRDF. We used high performance computer technology to optimize the input/output (I/O) and computation time on a multiprocessor system. The following sections describe the algorithms implemented in our study, the input dataset, results from the algorithms and, finally, the computational performance of the algorithms.

\section{BRDF algorithms implemented in this study}

The Walthall model describes the surface BRDF as a quadratic function of view, solar and relative azimuth angles (Walthall et al. 1985). This model has been widely tested using data from different land cover types and the model coefficients are derived empirically (e.g. Ranson et al. 1991, Russel et al. 1995, Walthall 1997). Nilson and Kuusk (1989) modified the Walthall model to satisfy the principle of reciprocity:

$$
\rho\left(\theta_{\mathrm{v}}, \theta_{\mathrm{s}}, \varphi_{\mathrm{v}}, \lambda\right)=a_{0}\left(\theta_{\mathrm{v}}^{2}+\theta_{\mathrm{s}}^{2}\right)+a_{1} \theta_{\mathrm{v}}^{2} \theta_{\mathrm{s}}^{2}+a_{2} \theta_{\mathrm{v}} \theta_{\mathrm{s}} \cos \varphi+a_{3}
$$

where $\rho\left(\theta_{\mathrm{s}}, \theta_{\mathrm{v}}, \varphi, \lambda\right)$ is the surface BRDF and $\theta, \varphi$ and $\lambda$ are the zenith and azimuth angles, and wavelength respectively. The subscripts $\mathrm{v}$ and $\mathrm{s}$ denote the angles of the sensor and the Sun respectively. $\varphi$ is the relative azimuth angle $\left(\varphi=\varphi_{\mathrm{v}}-\varphi_{\mathrm{s}}\right)$ and $a_{0-3}$ are the model coefficients. The coefficients in equation (2) are derived from a set of 
directional reflectances for each solar zenith angle by curve fitting using a leastsquares routine.

The second model we implemented is the CSAR model of Rahman et al. (1993a), which can be written as:

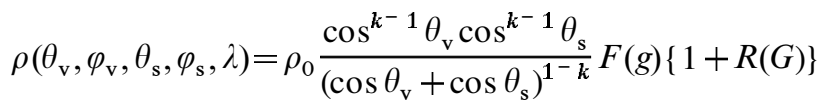

The first term on the right-hand side of equation (3) is a modified Minnaert (1941) function, and describes the variations in nadir reflectance $\left(\rho_{0}\right)$ with view and illumination angles. $k$ is an empirical parameter that ranges from 0 to 1 and indicates the level of surface anisotropy. The general shape of the BRDF is described by $k$, and a surface with lower value of $k$ is more anisotropic than a surface with higher values of the same. A one-parameter Henyey and Greenstein (1941) function is used to characterize the phase function:

$$
F(g)=\frac{1-\Theta^{2}}{\left\{1+\Theta^{2}-2 \Theta \cos (\pi-g)\right\}^{1.5}}
$$

where $\cos g=\cos \theta_{\mathrm{s}} \cos \theta_{\mathrm{v}}+\sin \theta_{\mathrm{s}} \sin \theta_{\mathrm{v}} \cos \varphi$ and $\Theta$ is an empirical value that determines the relative amount of forward and backward scattering.

The factor $1+R(G)$ accounts for the hot spot in the backscatter direction and is formulated as:

$$
1+R(G)=1+\frac{1-\rho_{0}}{1+G}
$$

where

$$
G=\left(\tan ^{2} \theta_{\mathrm{v}}+\tan ^{2} \theta_{\mathrm{s}}-2 \tan \theta_{\mathrm{s}} \tan \theta_{\mathrm{v}} \cos \varphi\right)^{1 / 2}
$$

Thus, the CSAR model has three unknown parameters- $\rho_{0}, k$ and $\Theta$ - which have to be determined by model inversion and numerical iteration. Both the modified Walthall model and the CSAR model have been adopted to generate BRDF and albedo products from MODIS and MISR instruments on the EOS-AM (Terra) platform (Diner et al. 1996, Strahler et al. 1999). To minimize the computational complexity of the CSAR model in the operational retrieval of BRDF from MISR data, a modified version of equation (3) is used to allow a nearly linearizable leastsquares solution in the derivation of model parameters. Nevertheless, the CSAR model is still computationally more intensive than the modified Walthall model. In our analysis, we implemented the original CSAR algorithm as given by equation (3).

The modified Walthall model and the CSAR model assume that variations in surface reflectance are caused by changes in viewing and illumination geometry only. It is supposed that the target does not change significantly over the period of measurement. However, land cover types such as grasslands and deciduous forests exhibit seasonality, and a temporal BRDF model is thus required to account for phenological variations of the land surface. The temporal BRDF model of Liang and Townshend (1997) uses Fourier techniques to account for variations in surface phenology, and this is the third model that we used in this study. This model is an 
extension of the modified Walthall model and has eight coefficients: four for the modified Walthall model and four for the temporal function:

$$
\begin{aligned}
\rho\left(\theta_{\mathrm{s}}, \theta_{\mathrm{v}}, \varphi, \lambda\right) & =a_{0}\left(\theta_{\mathrm{v}}^{2}+\theta_{\mathrm{s}}^{2}\right)+a_{1}\left(\theta_{\mathrm{v}}^{2} \theta_{\mathrm{s}}^{2}\right)+a_{2}\left(\theta_{\mathrm{v}} \theta_{\mathrm{s}} \cos \varphi\right) \\
& +a_{3}+a_{4} \cos \left(\frac{2 \pi t}{N}\right)+a_{5} \sin \left(\frac{2 \pi t}{N}\right)+a_{6} \cos \left(\frac{4 \pi t}{N}\right)+a_{7} \sin \left(\frac{4 \pi t}{N}\right)
\end{aligned}
$$

The coefficients $a_{0-7}$ are derived by a statistical least-squares method as in the modified Walthall model. $N$ is the number of measurements in a year and $t$ varies from 0 to $N-1$.

\section{Input data}

We used the PAL dataset (James and Kalluri 1994) from 1983 to 1986 to retrieve global BRDF. The PAL dataset is a consistently calibrated and processed global AVHRR dataset and has a spatial resolution of $8 \mathrm{~km}$. Although PAL data are available as daily and ten-day maximum value Normalized Difference Vegetation Index (NDVI) composites, only the composites were used in our study in order to minimize the effects of cloud and atmospheric contamination (Holben 1986). There are twelve data layers for each compositing period, which consist of the following variables: consistently calibrated reflectances and brightness temperatures from the five bands of the AVHRR, NDVI, scan and Sun geometry for each pixel, Earth location, cloud and quality flags, and date of observation. The visible and nearinfrared (NIR) reflectances have been corrected for Rayleigh scattering and ozone absorption. Each ten-day composite image is about 225 Mbytes, and there are 36 composites in an year. PAL data are available for the time period 1981 to 1999. However, several processing errors have been subsequently detected in the dataset (Smith and Kalluri 1997); we only used data from 1983 to 1986, since at the time of our analysis, only data for this time period had been corrected for processing errors. In spite of its limitations, the PAL data is the only global data set that is available which is suitable for this study.

\section{Algorithm implementation}

As previously mentioned, the modified Walthall model and the CSAR model assume that the land surface is invariant during the time of observations. Because we used multi-temporal observations in our analysis, we had to characterize surface anisotropy at discrete time intervals. To minimize the effects of changing surface phenology on BRDF retrieval from these two algorithms, the PAL data from 1983 to 1986 were divided into four quarters: January-March, April-June, July-September and October-December. Each quarter contains data grouped from all the four years. Increasing the temporal resolution by more than three months introduced phenological effects in the BRDF signal, while at the same time decreasing the time period by less than three months did not provide enough observations to determine the BRDF accurately. Cloud-free pixels were selected from each quarter using the CLAVR (Clouds from AVHRR) flags (Stowe et al. 1991) in the PAL dataset, and only these pixels were used in determining the BRDF coefficients for each quarter.

Using the clear pixels from each quarter, the coefficients of the modified Walthall model and the CSAR model were determined by inversion of equations (2) and (3). Simply stated, the inversion algorithm determines the coefficients of the model so that the estimated reflectances best fit the observed values. The derived coefficients 
should minimize the merit function, which is the cumulative squared difference between the observed values and model predicted values, that is

$$
\varepsilon^{2}=\sum_{i=1}^{n}\left(\rho_{i}-\hat{\rho}_{i}\right)^{2}
$$

where $\rho_{i}$ is the observed reflectance from the input dataset, $\hat{\rho}_{\boldsymbol{i}}$ is the modelled reflectance and $n$ is the total number of observations over a given target. Because of the linear relationship between the independent parameters and the reflectances in the modified Walthall model, this model can be solved using a linear least-squares regression analysis. However, due to the nonlinear nature of the CSAR model, we used Powell's (1964) method to minimize the merit function. Powell's method has been previously used in inversion of BRDF models (e.g. Kuusk 1991, Liang and Strahler 1993, 1994). Starting with some initial guess values of the model coefficients, Powell's method iterates until the error term is minimized. The number of iterations needed to find the minima depends on how close the initial guesses are to the final solution. The closer the initial guesses are to the final solution, the fewer iterations are needed. The final solution is not affected by the initial guess values, but the time to find the solution is affected. For a detailed description of implementing Powell's method on this dataset, the interested reader is referred to Zhang et al. (1998). Using samples of pixels from different land cover classes (DeFries et al. 1998) an initial average estimate of the model coefficients was derived, and these estimated values were then used as starting guess values for all the pixels within that land cover type throughout the globe. Since the temporal model (4) describes the variations in surface reflectance as a continuous function of time, the input data are not divided into discrete time intervals, and all the cloud-free data are used to derive coefficients that are valid for all the twelve months.

The following global images are generated as output from each model: model coefficients, standard errors of model predicted reflectances in channels 1 and 2 and NDVI, the correlation coefficients $\left(R^{2}\right)$ from the least-squares regression equations that were used to derive the model coefficients, and the number of points used to derive the model coefficients.

The input data consist of nine global images per composite, including the reflectance and geometry layers, where each image is a two-dimensional array of $5004 \times 2168$ pixels. There are thirty six composites in a year, and the total data volume for the four-year time period is 27 Gbytes consisting of 1296 images. All the three algorithms were implemented on an IBM SP 2 computer with 16 processors. Each node on the SP2 machine has six 2.2 GB SCSI disks, and all the nodes are connected by a high performance switch. The algorithms were designed in the Single Program Multiple Data (SPMD) model, where each processor executes the same code on different parts of the image. Optimum computational performance was achieved by minimizing the total I/O time of data transfer between disks and memory, balancing the computational loads among different nodes, and finally minimizing the communication among the nodes This was achieved by partitioning the input data equally among the 16 processors of the machine. We efficiently laid out the 1296 input images on the available disks, accessed them once, extracted the land data and redistributed them among the nodes. Thus, the I/O and communication between the nodes were minimized (Zhang et al. 1998). 


\section{Results and discussion}

In this section we first discuss the performance of the three BRDF models at a global scale by comparing the standard errors between predicted reflectances from each model with reflectances measured by AVHRR in channels 1 and 2 . We then present the benchmark results of the three models on single and multiprocessor computer environments. Finally, we examine the spatial distribution of model coefficients to see if there is any correlation between the land cover and BRDF coefficients.

We compare the model's performance at a global scale using histograms of standard errors. At the global scale there are no known BRDF datasets available at $8 \mathrm{~km}$ spatial resolution in order to compare and validate our results. Standard errors, root mean square errors and relative errors are the commonly used statistics to measure a model's performance and have been used by several authors to test BRDF models (see, for example, Kimes et al. 1987, Liang and Strahler 1994, Privette et al. 1996). A model's performance is gauged by testing its ability to match measured reflectances (Privette et al. 1997). The standard error between measured $\left(\rho_{\lambda}\right)$ and modelled $\left(\hat{\rho}_{\lambda}\right)$ reflectances is expressed as:

$$
\text { Standard error }=\sqrt{\frac{\sum_{i=1}^{N}\left(\rho_{\lambda}-\hat{\rho}_{\lambda}\right)^{2}}{N}}
$$

where $N$ is the total number of measurements used to derive the coefficients for any location.

A comparison of the standard errors between the predicted reflectances from the three BRDF models and reflectances measured by the AVHRR in channels 1 and 2 is shown in figure 1 for the third quarter (July-September). For the modified Walthall and the CSAR models, the reflectances were modelled using the coefficients derived for the third quarter. However, for the temporal model, a single set of coefficients applicable for the entire duration of the dataset was derived, and these coefficients were used to model the reflectances for the third quarter. The histograms of the standard errors show that all the models perform very similarly at a global scale for the dataset we analysed.

Comparison of standard errors in reflectances from the modified Walthall model and the CSAR model for the third quarter (July-September) are shown in figures $2(a)-2(d)$ for thirteen global land cover classes (table 1). In this analysis, the global land cover classification map of DeFries et al. (1998) was used. The box plots in figure 2 show the statistical distribution of the standard errors. The lower boundary of the box closest to zero indicates the 25 th percentile, and the upper boundary of the box farthest from zero indicates the 75 th percentile. The thin line within the box shows the median of the data, while the thick line shows the mean. Whiskers above and below the box indicate the 90th and 10th percentile respectively. Both the modified Walthall model and the CSAR model had the lowest mean standard error of derived reflectances over wooded grasslands and shrublands (Class 7) in channel 1 as well as in channel 2 . When we compare the statistical distribution of the standard errors within each land cover class, in general, the variation in the standard errors of reflectances derived by the CSAR model was more than those derived by the modified Walthall model; that is, for each land cover type, both the box and the whiskers on the plots for the CSAR model are longer than those for the modified 

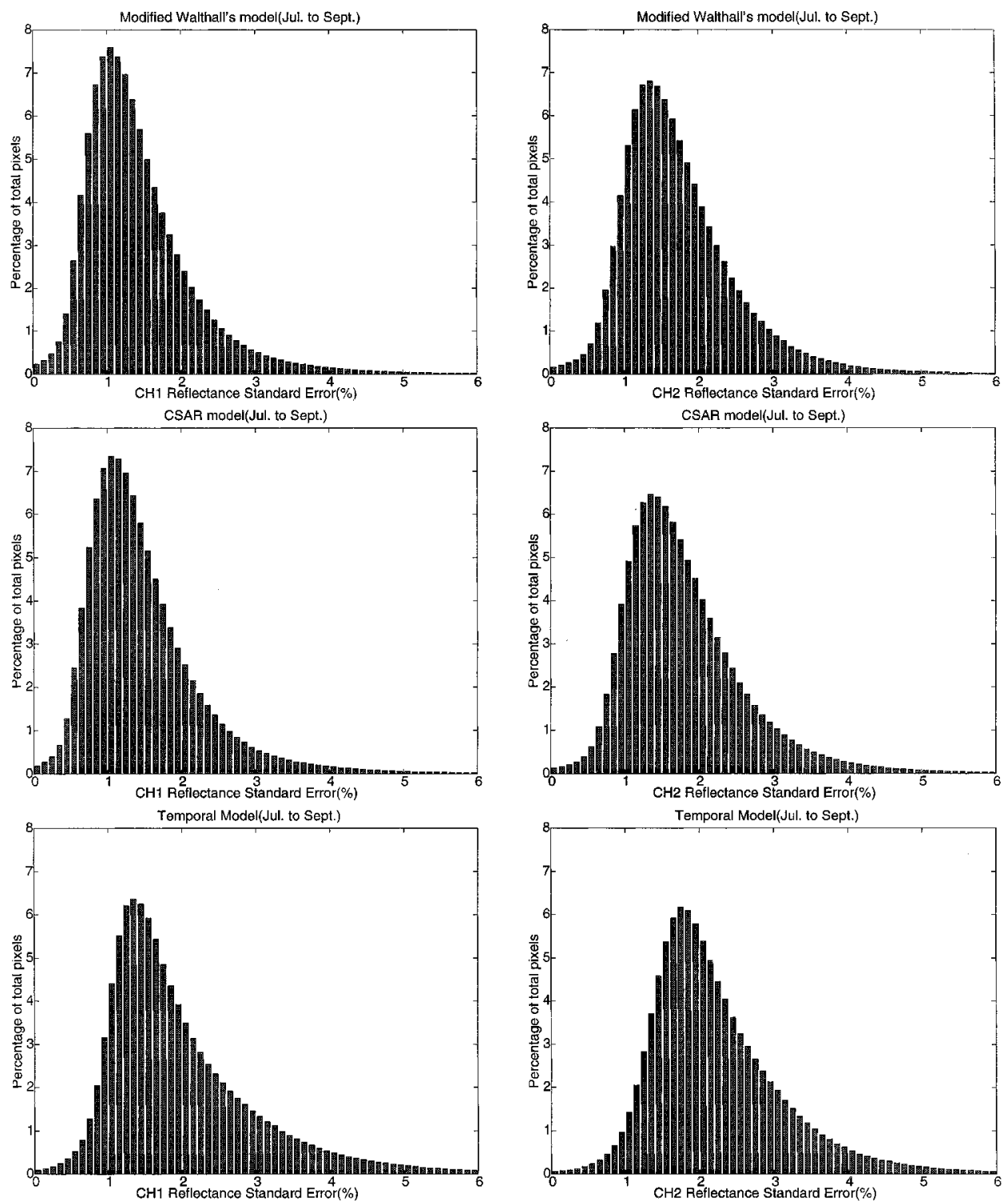

Figure 1. Comparison of standard errors in channel 1 and 2 reflectances from all the three models for the third quarter (July-September) during 1983-1986 for the whole globe. For the temporal model, we used data from all four years to derive the model coefficients and applied them to compute the reflectances and standard errors for the third quarter.

Figure 2. Comparison of standard errors in channel 1 and 2 reflectances for 13 land cover classes. (a) Standard errors in Channel 1 reflectances from the modified Walthall model. (b) Standard errors in Channel 2 reflectances from the modified Walthall model. (c) Standard errors in Channel 1 reflectances from the CSAR model. (d) Standard errors in Channel 2 reflectances from the CSAR model. Data shown here is for the third quarter (July-September) during 1983-1986. The land cover types are given in table 1 . 


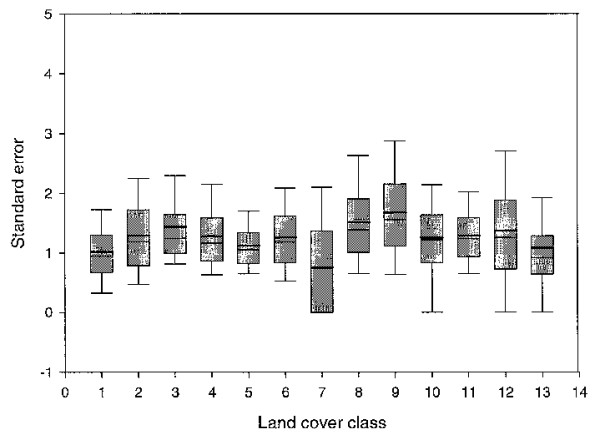

(a)

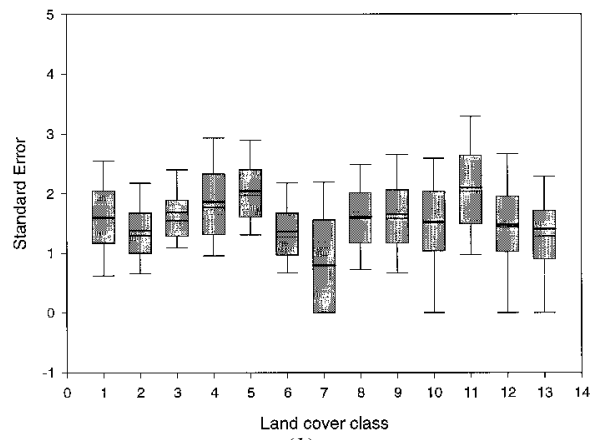

(b)

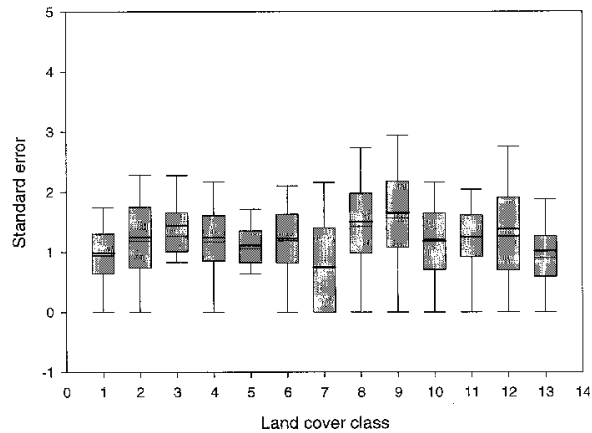

(c)

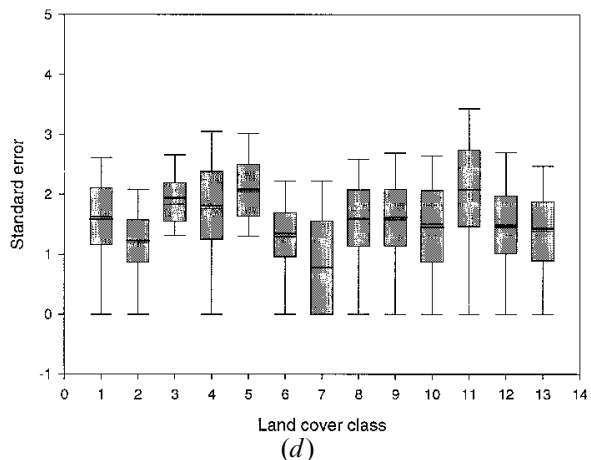


Table 1. Definition of global land cover classes from DeFries et al. (1998).

\begin{aligned} & \hline 1 Evergreen needleleaf forests \\ & 2 Evergreen broadleaf forests \\ & 3 Deciduous needleleaf forests \\ & 4 Deciduous broadleaf forests \\ & 5 Mixed forests \\ & 6 Woodlands \\ & 7 Wooded grasslands/shrublands \\ & 8 Closed bushlands or shrublands \\ & 9 Open shrublands \\ & 10 Grasses \\ & 11 Croplands \\ & 12 Bare \\ & 13 Mosses and lichens \\ & \hline\end{aligned}

Walthall model. For all the land cover classes, standard errors in reflectances were higher in channel 2 than in channel 1. Among different land covers, crop lands (Class 11) and mixed forests (Class 5) had high mean standard errors in channel 2 reflectances from both the CSAR and modified Walthall models. Open shrub lands (Class 9) had the highest mean error in channel 1 reflectances from both the models.

Figure 3 shows the standard errors between predicted reflectances from all the three models and measured reflectances in AVHRR bands 1 and 2 over Asia and parts of the Sahara when the data from the four years are used together in deriving the BRDF, i.e. the input data are not divided into quarters. Figure 3 shows that over seasonally invariant land cover types such as deserts, all the models perform equally well, whereas in higher latitude areas with deciduous vegetation that has a strong seasonal variation, the temporal model performs better as shown by the substantially smaller standard errors. Seasonal variations in surface conditions introduced errors in characterizing the BRDF by the modified Walthall model and the CSAR model. Thus, the temporal model has a distinct advantage over the other two models since it does not require the division of data into discrete time intervals, and a single set of coefficients from this model can be applied to estimate the BRDF at any given time.

For the modified Walthall model, 3600 Floating Point Operations (FLOPs) are required per pixel to derive the coefficients. In comparison, the CSAR model is computationally more expensive because of its iterative nature, and requires 3.9 MFLOPs per pixel. Thus, for the 2.5 million land pixels in the PAL dataset, 9 GFLOPs are required to solve the modified Walthall model, 9750 GFLOPs for the CSAR model, and 40 GFLOPs to solve the temporal model. Given the peak performance of 266 MFLOP s per second of a single RS6000 processor, our estimates indicate that $3 \mathrm{~h} 16 \mathrm{~min}$ processing time is required to determine the coefficients of the modified Walthall model using a single CPU. Using a single CPU requires about $42 \mathrm{~h}$ to solve the BRDF for the CSAR model and $3 \mathrm{~h} 28 \mathrm{~min}$ to solve the temporal model.

On the IBM SP2 computer configuration described in $\$ 4$, about $159 \mathrm{~min}$ are needed to run the CSAR model for the global dataset, while only $16 \mathrm{~min}$ are required to determine the BRDF coefficients for the modified Walthall model for each quarter (table 2). We achieved a performance rate of 0.9 GFLOPS for the modified Walthall model, and 1.2 GFLOPS for the CSAR model on the SP2, when all the 16 processors 
Channel 1 Standard Error

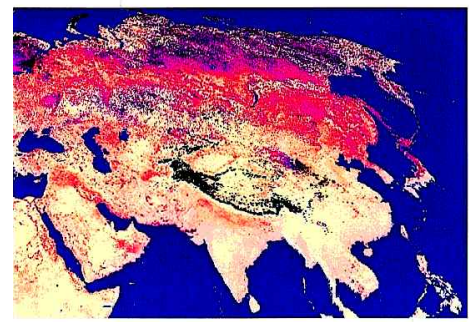

Modified Walthall model

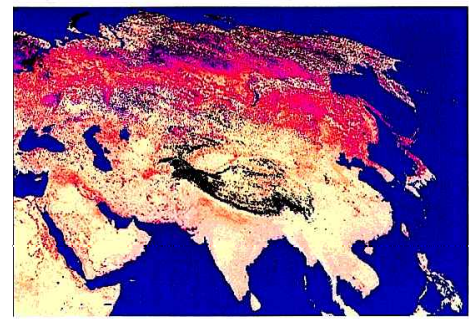

CSAR model

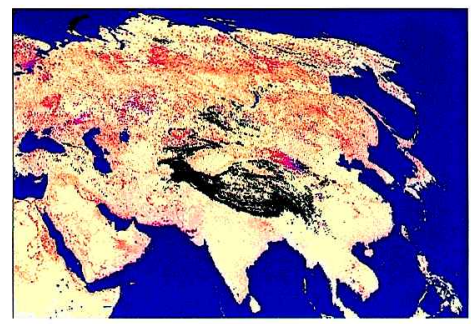

Temporal model
Channel 2 Standard Error

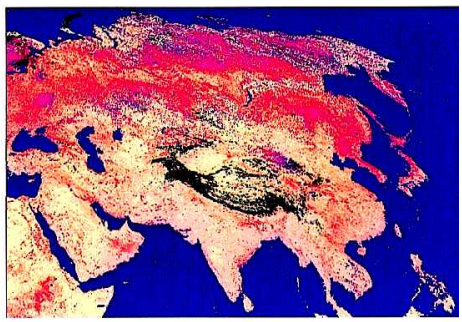

Modified Walthall model

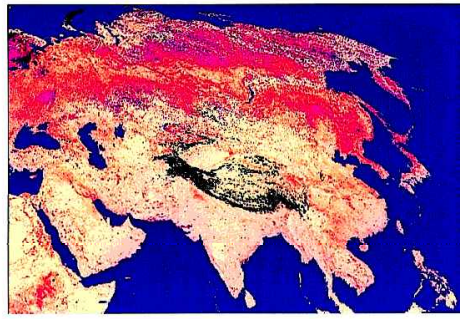

CSAR model

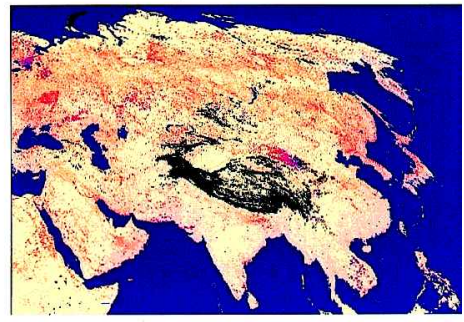

Temporal model

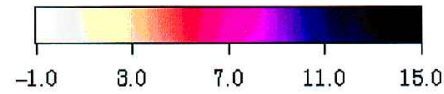

Standard Errors in Retrieved Reflectances $(\%)$

Figure 3. Spatial distribution of standard errors in AVHRR channels 1 and 2 reflectances from all the three models when the input data from 1983-1986 were used together, i.e. the input data were not divided into quarters for retrieving the BRDF. Parts of North Africa and Asia are shown in this image.

are used. The time taken to solve the temporal model using all the 16 nodes is $18 \mathrm{~min}$. Table 2 lists the benchmark results of running time for the three BRDF models in single and multiprocessor computational environments and shows that the time spent in data $\mathrm{I} / \mathrm{O}$ is similar for all the models. However, the computational time is significantly different.

Figures 4 and 5 show the BRDF coefficients for AVHRR channels 1 and 2 respectively for the modified Walthall model. These coefficients are for the third quarter (July-September) during 1983-1986. For the first time to our knowledge, these images show the coefficients of a BRDF model at a global scale. In general, the spatial structure of coefficients $a_{0-2}$ is less coherent among different land cover types, and their images are more 'noisy' compared to the coefficient $a_{3}$ which 
Table 2. Running time (minutes) for the three BRDF models in single and multiprocessor computational environments. Each CPU is an IBM RS6000 processor with a peak performance of 266 MFLOPS.

\begin{tabular}{|c|c|c|c|c|c|c|}
\hline & \multicolumn{2}{|c|}{$\begin{array}{l}\text { Modified Walthall } \\
\text { model }\end{array}$} & \multicolumn{2}{|c|}{ CSAR model } & \multicolumn{2}{|c|}{ Temporal model } \\
\hline & $\begin{array}{c}1 \\
\text { processor }\end{array}$ & $\begin{array}{c}16 \\
\text { processors }\end{array}$ & $\begin{array}{c}1 \\
\text { processor }\end{array}$ & $\begin{array}{c}16 \\
\text { processors }\end{array}$ & $\begin{array}{c}1 \\
\text { processor }\end{array}$ & $\begin{array}{c}16 \\
\text { processors }\end{array}$ \\
\hline $\mathrm{I} / \mathrm{O}$ & 190 & 15 & 190 & 14 & 193 & 16 \\
\hline Computation & 2.0 & 0.5 & 2300.00 & 144 & 11 & 1 \\
\hline Communication & 4 & 0.5 & 4 & 0.5 & 4 & 1 \\
\hline Total & 196 & 16 & 2494 & 158.5 & 208 & 18 \\
\hline
\end{tabular}

represents the nadir reflectance value for an overhead Sun in the individual AVHRR bands for this model. Coefficients $a_{0-2}$ cannot be linked to any particular physical attribute of the land cover. The spatial patterns of $a_{3}$ shown here are consistent with different land cover classes (e.g. DeFries and Townshend 1994). Densely vegetated areas (e.g. central Africa, Brazil, temperate and boreal forests in Asia and Europe) and agricultural regions (e.g. central USA) show high reflectances in channel 2 and very low reflectances in channel 1 . Deserts, on the other hand, show high reflectances in both the bands (e.g. Sahara, central Australia, Kalahari). The polar ice caps, and the mountainous regions of the Himalayas, Andes and the Rockies have null values due to insufficient data.

Figure 6 shows a global image of the total number of 'cloud-free' observations used to derive the BRDF for each pixel in the modified Walthall model and the CSAR model for the third quarter. From this image it is apparent that the CLAVR algorithm is a poor discriminator of clouds in areas covered by snow and ice (such as the higher latitudes and the mountainous regions) because of the similarity in the spectral signatures of snow and clouds in the reflective and thermal wavelengths. In spite of using composite data, there are only a few cloud-free observations in the tropics. The number of cloud-free points shown in figure 6 is consistent with the global cloud climatology data produced by the International Satellite Cloud Climatology Project (ISCCP) (http://ingrid.ldeo.columbia.edu/SOURCES/.ISCCP/).

Parameters $\rho_{0}, k$ and $\Theta$ for channels 1 and 2 in the CSAR model are shown in figures 7 and 8 respectively. Although these parameters are empirically derived and do not have a physical meaning associated with them, each parameter controls a particular mathematical function that describes the shape of the BRDF under a range of view and illumination conditions. Figures 7 and 8 show that these coefficients are more closely related to the land cover type and exhibit a strong spatial structure compared to the coefficients of the modified Walthall model since the mathematical functions in the CSAR model are based on a conceptual understanding of the physical nature of interaction between the radiation regime and the surface. $\rho_{0}$ represents the intensity of the surface reflectance, but cannot be considered as either a single scattering albedo or a normalized reflectance (Rahman et al. 1993a), though pixels with a larger value of $\rho_{0}$ can be considered to be more reflective than those with lower values of $\rho_{0}$ at a particular wavelength. The degree of surface anisotropy is described in the CSAR model by the parameter $k$. Surfaces with lower values of $k$ are relatively more anisotropic than those with higher values of $k$. As expected, 

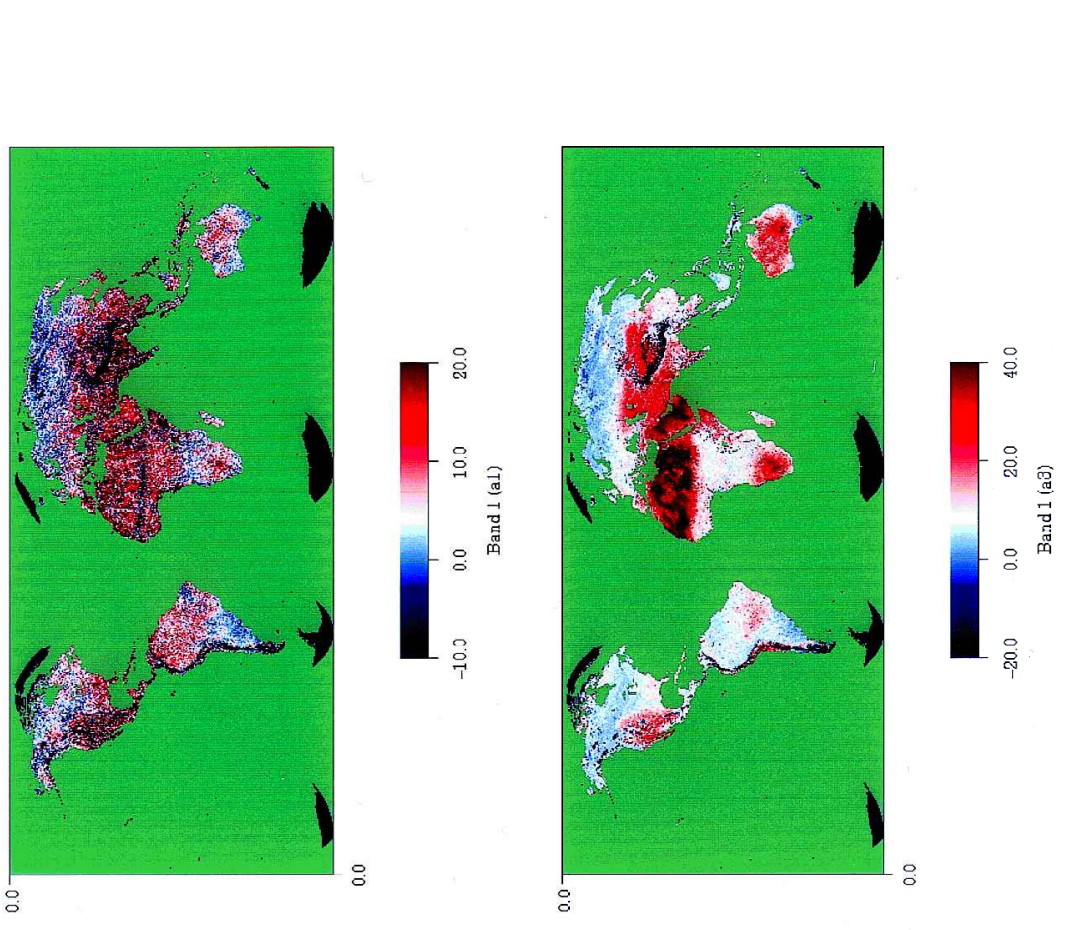

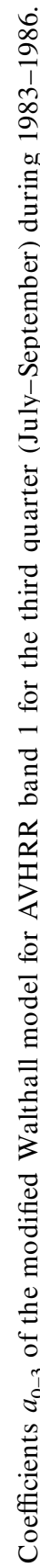
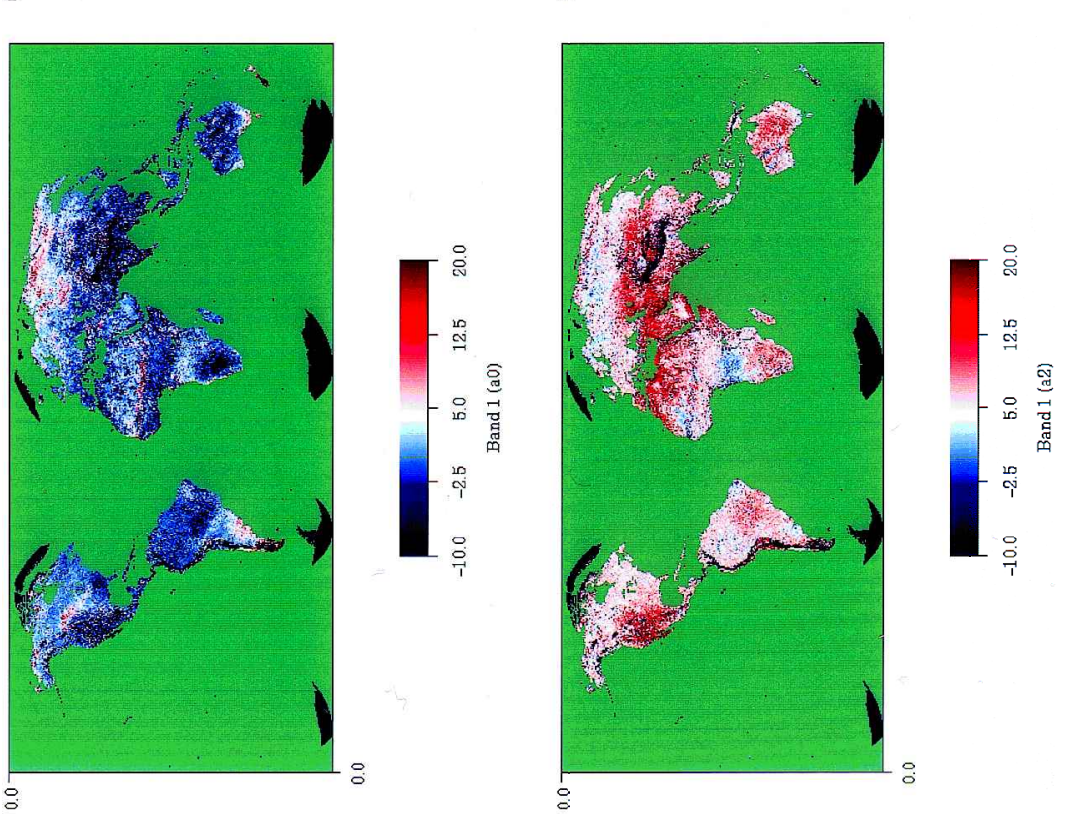

㐫 

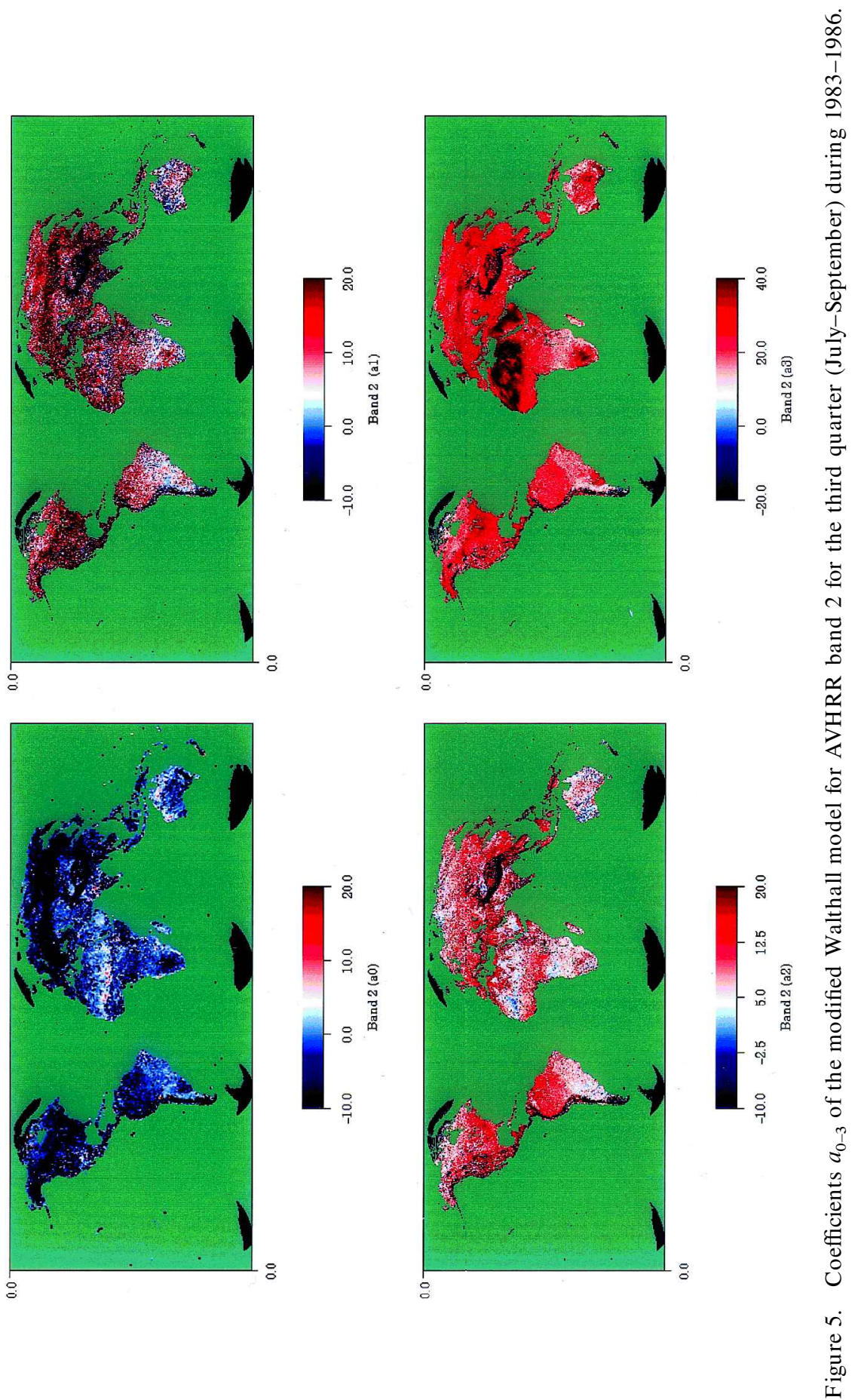

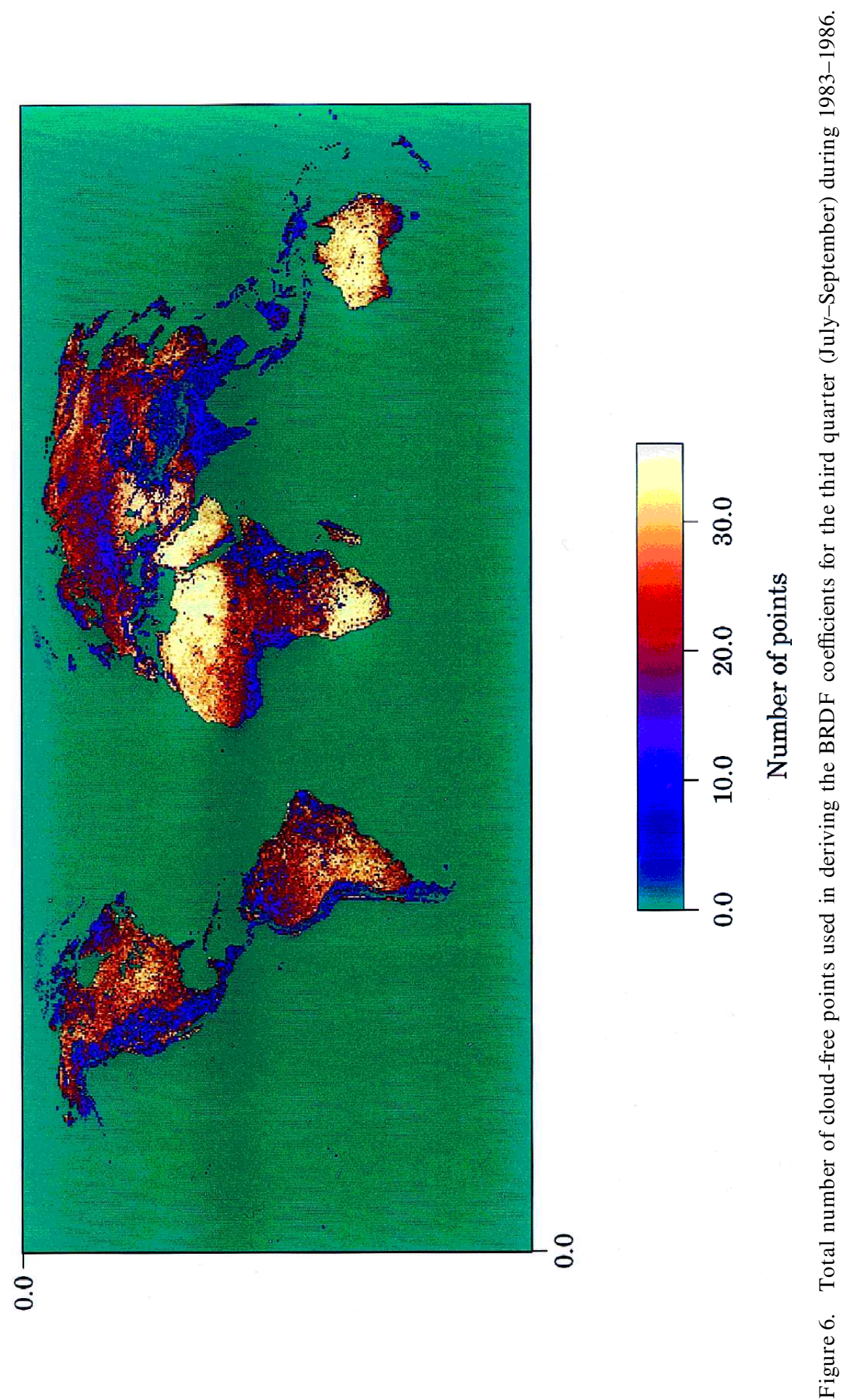
Coefficient $\rho_{0}$ (Band 1)

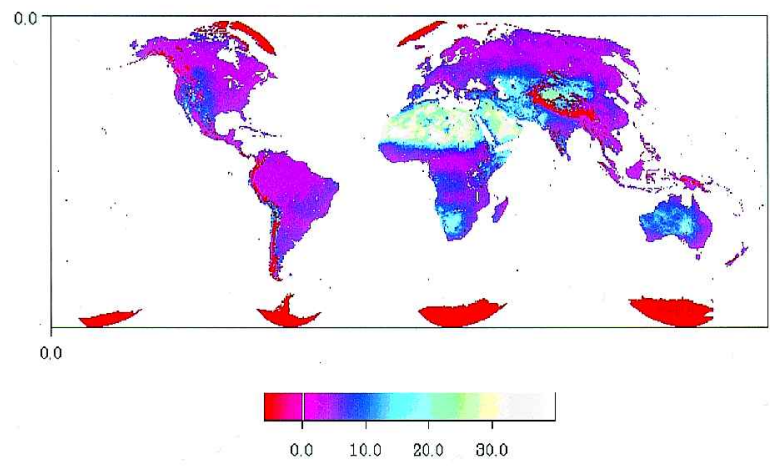

Coefficient $k$ (Band 1)

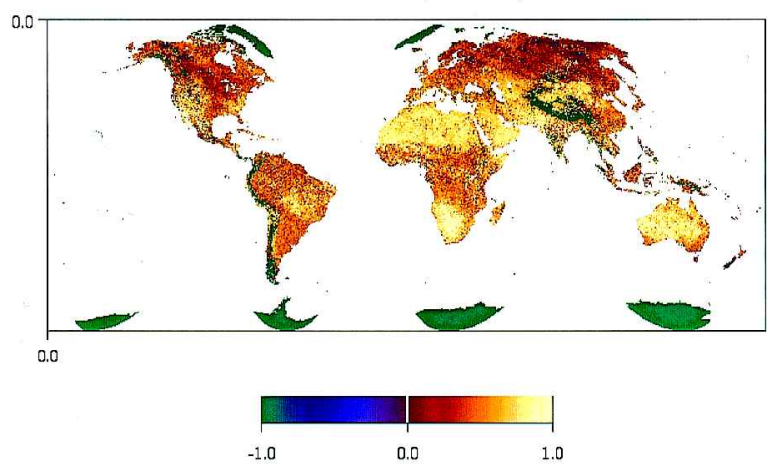

Coefficient $\Theta$ (Band 1)

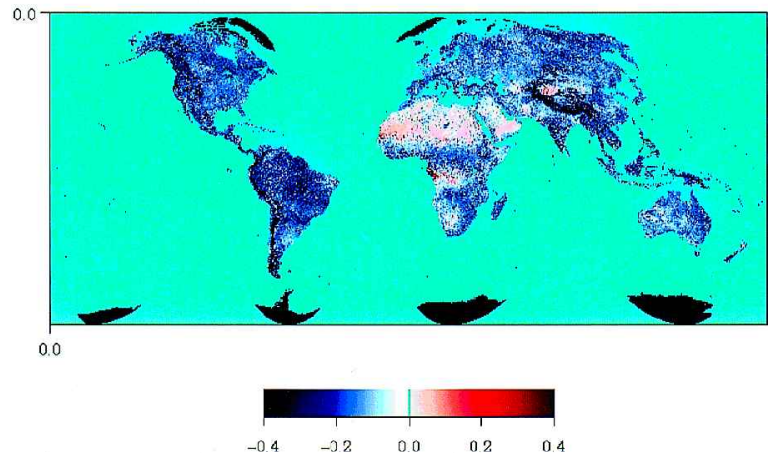

Figure 7. Parameters $\rho_{0}, k$ and $\Theta$ for AVHRR channel 1 of the CSAR model for the third quarter (July-September) during 1983-1986.

figures 7 and 8 show that vegetated areas are more anisotropic than deserts, and reflectances from vegetation are more directional in the visible wavelength than in the NIR wavelength. The parameter $\Theta$ controls the relative amount of forward $(0 \leqslant \Theta \leqslant+1)$ and backward $(-1 \leqslant \Theta \leqslant 0)$ scattering of reflected radiation. Most pixels in figures 7 and 8 have a narrow range of $\Theta$ (from -0.4 to 0.2 ), indicating that the azimuthal dependence of the BRDF is small. Results from the dataset we used show that deserts predominantly have positive values (forward scattering) 


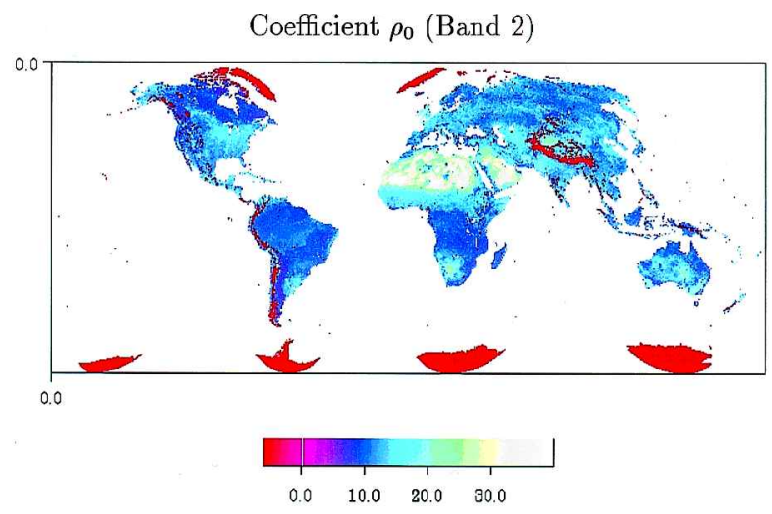

Coefficient $k$ (Band 2)

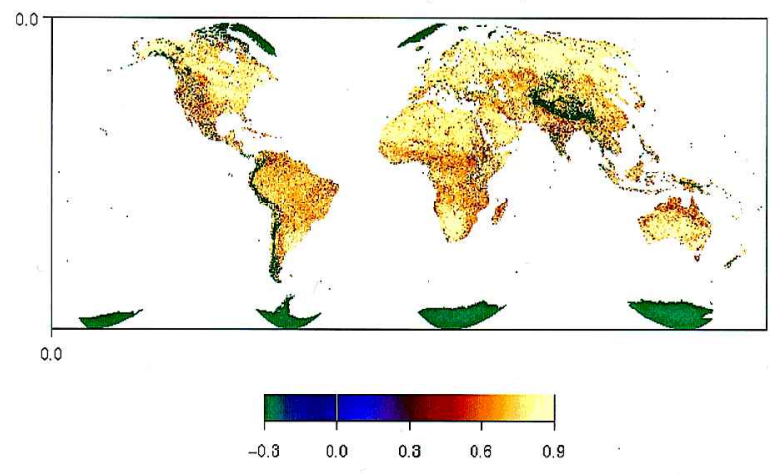

Coefficient $\Theta$ (Band 2)

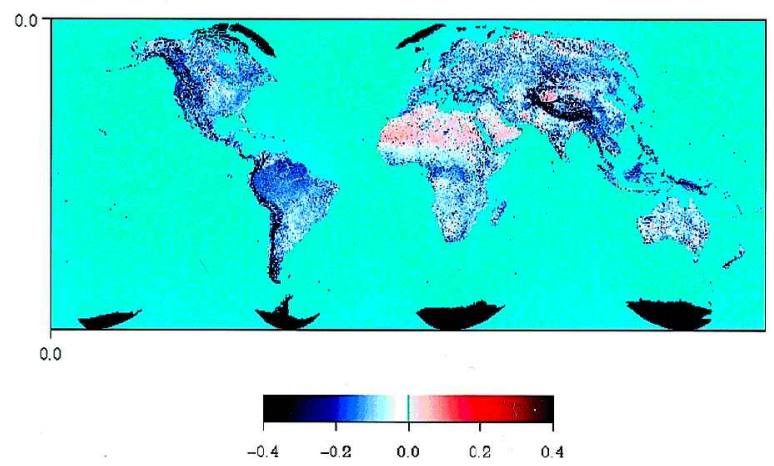

Figure 8. Parameters $\rho_{0}, k$ and $\Theta$ for AVHRR channel 2 of the CSAR model for the third quarter (July-September) during 1983-1986.

whereas vegetated areas mostly have negative values of $\Theta$ (backward scattering). Verstraete and Flasse (1996) observed similar spatial patterns of the CSAR model coefficients over Africa derived from a series of twenty AVHRR images.

The Fourier coefficients $\left(a_{4-7}\right)$ for channel 1 of the temporal model are shown in figure 9. These coefficients of the Fourier transform can be used to generate the amplitude and phase images of the time series satellite data that describe the 

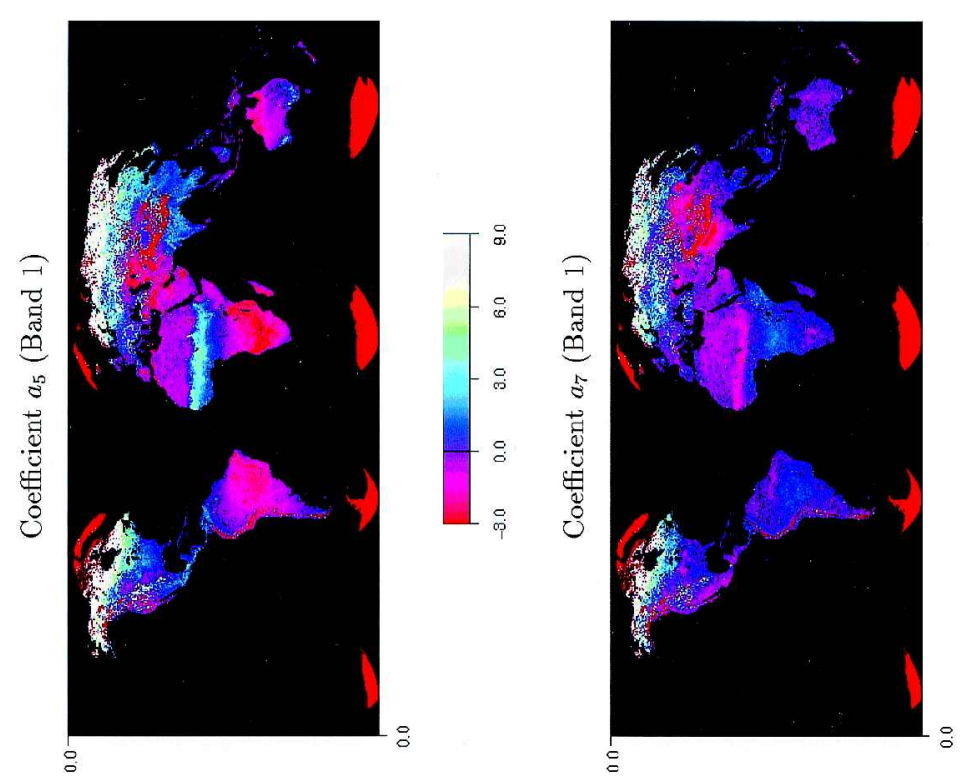

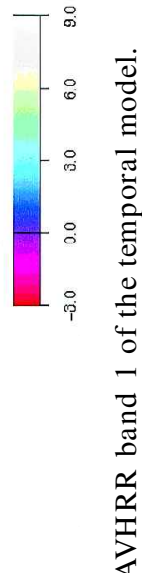
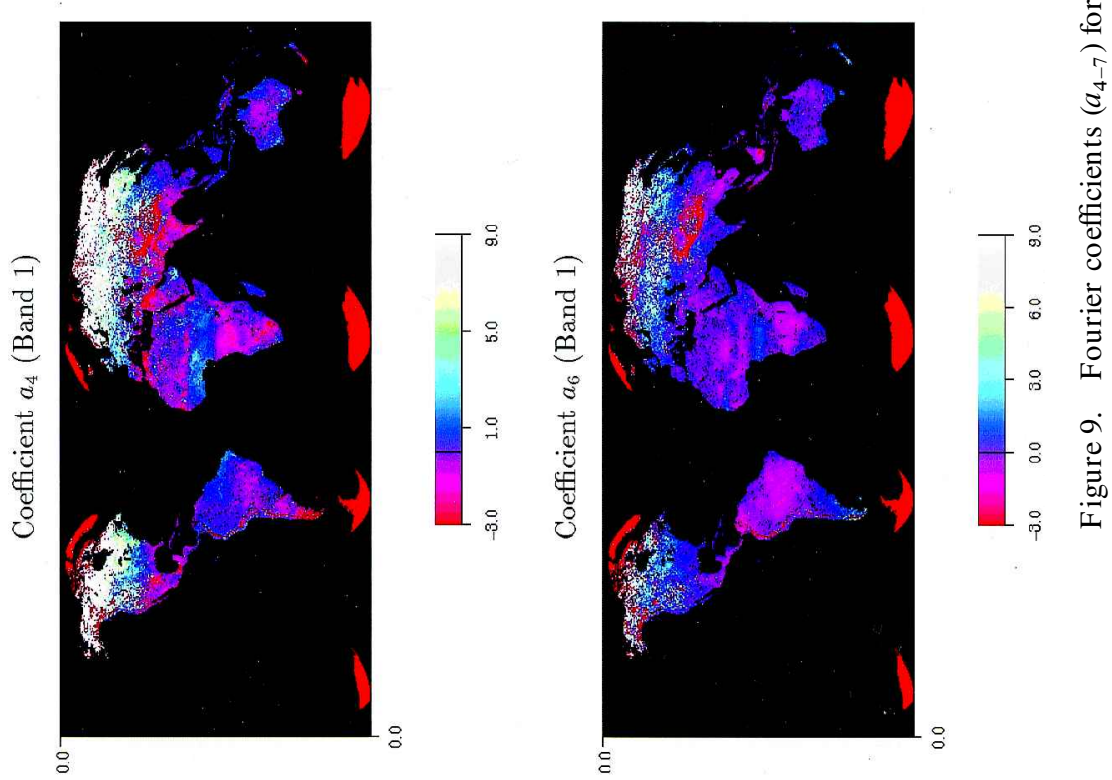
phenological variations in land cover, and can thus be used to discriminate between different land cover classes (e.g. Menenti et al. 1993, Verhoef et al. 1996). It can be seen from figure 9 that the Fourier coefficients exhibit a strong spatial pattern corresponding to variations in vegetated and non vegetated areas, and the coefficients have higher values over areas covered by deciduous vegetation which has pronounced phenology compared with evergreen vegetation.

\section{Summary and conclusions}

Using high performance computing, we have demonstrated the feasibility of implementing complex as well as simple BRDF models at a global scale. The results from our study can be summarized as follows.

- All the three BRDF models tested here performed similarly well as measured by the standard error of reflectances with AVHRR data when applied at discrete time intervals. However, when the input data were not divided into discrete time intervals, the temporal model gave better results.

- In spite of using composite data, several pixels were flagged as cloudy by CLAVR, especially over mountainous or snow covered areas.

- Standard errors from the modified Walthall model and the CSAR model were generally higher in channel 2 compared to channel 1 for all land cover types.

- The CSAR model was computationally complex, and took roughly ten times longer than the other two models to execute on a 16 node parallel processor. However, the results from the CSAR model were not significantly better than those of the other two.

- For the modified Walthall model, coefficient $a_{3}$ showed a stronger association with land cover compared to the other three coefficients of the same model whose spatial structure was more noisy. The three coefficients of the CSAR model and the Fourier coefficients of the temporal model showed a well defined spatial structure corresponding to variations in land cover.

The implementation of complex BRDF algorithms using frequent high-resolution satellite data generating many variables and statistics for each pixel will lead to greater data processing demands which can only be handled by high performance computing power. Our results demonstrate that a significant reduction in run time can be achieved in solving the BRDF algorithms by using high performance computer technology.

Although the empirically derived coefficients for the CSAR and temporal models show a strong association with land cover, further investigation is necessary to fully interpret their physical meaning at a global scale. If the objective of deriving BRDF data is to correct multiangular measurements and to estimate albedo, then our analysis shows that a simple model such as the modified Walthall model will suffice. However, if we wish to characterize land cover based on the BRDF coefficients, then we need a more complex model where the coefficients are related to the physical state of the target. The availability of a sufficient number of cloud-free observations to derive the BRDF coefficients within a time frame during which the phenology does not change significantly is a problem in several parts of the world. Our results show that this problem could be overcome by using a temporal model. The results from this study are unique, and are expected to provide valuable inputs into BRDF retrieval algorithms proposed for EOS instruments such as MODIS and MISR.

\section{Acknowledgments}

This research is supported by a grant from the National Science Foundation (BIR 9318183). We wish to thank Dr Peng Gong for his help with the review process 


\section{References}

Braswell, B. H., Schimel, D. S., Privette, J. L., Moore III, B., Emery, W. J., Sulzman, E. W., and HUDAK, A. T., 1996, Extracting ecological and biophysical information from AVHRR optical data: an integrated algorithm based on inverse modeling. Journal of Geophysical Research, 101, 23335-23348.

Burgess, D. W., and PAIRMAN, D., 1997, Bidirectional reflectance effects in NOAA AVHRR data. International Journal of Remote Sensing, 18, 2815-2825.

CIHLAR, J., MANAK, D., and VoISIN, N., 1994, AVHRR bidirectional reflectance effects and compositing. Remote Sensing of Environment, 48, 77-88.

DEFRIES, R. S., and TOWNSHEND, J. R. G., 1994, NDVI-derived land cover classifications at a global scale. International Journal of Remote Sensing, 15, 3567-3586.

Defries, R. S., HAnsen, M., Townshend, J. R. G., and Sohlberg, R., 1998, Global land cover classification at $8 \mathrm{~km}$ spatial resolution: the use of training data derived from Landsat imagery in decision tree classifiers. International Journal of Remote Sensing, 19, 3141-3168.

Diner, D. J., D AVIES, R., Varnai, T., Borel, C., and Gerstl, S. A. W., 1996, MISR-Level 2 Topof-Atmosphere albedo algorithm theoretical basis. JPL: D-13401, Rev. B, URL: http://eospso.gsfc.nasa.gov/atbd/misrtables.html

Goward, S. N., Markham, B., Dye, D. G., Dulaney, W., and Yang, J., 1991, Normalized difference vegetation index measurements from advanced very high resolution radiometer. Remote Sensing of Environment, 35, 259-279.

GutMan, G. G., 1991, Vegetation indices from AVHRR: an update and future prospects. Remote Sensing of Environment, 35, 121-136.

HeNYey, L. G., and GreEnsteIn, T. L., 1941, Diffuse radiation in the galaxy. Astrophysical Journal, 93, 70-83.

HolBen, B., 1986, Characteristics of maximum-value composite images from temporal AVHRR data. International Journal of Remote Sensing, 7, 1417-1434.

James, M. E., and KalluRi, S. N. V., 1994, The Pathfinder AVHRR land data set: an improved coarse resolution data set for terrestrial monitoring. International Journal of Remote Sensing, 15, 3347-3364.

KIMES, D. S., SELLERS, P. J., and DiNER, D. J., 1987. Extraction of spectral hemispherical reflectance (albedo) of surfaces from nadir and directional reflectance data. International Journal of Remote Sensing, 8, 1727-1746.

KUUSK, A., 1991, The determination of vegetation canopy parameters from optical measurements. Remote Sensing of Environment, 37, 207-218.

Lewis, P., Barnsley, M. J., Sutherland, M., and Muller, J.-P., 1995, Estimating land surface albedo in the HAPEX-Sahel Experiment: model-based inversion using ASAS. International Geoscience and Remote Sensing Symposium, Florence, Italy, 10-14 July 1995 (Piscalaway, NJ: IEEE), pp. 2221-2223.

Li, Z., Cihlar, J., Zheng, X., Moreau, L., and Ly, H., 1996, The bidirectional effects of AVHRR measurements over Boreal regions. IEEE Transactions on Geoscience and Remote Sensing, 34, 1308-1322.

Liang, S., and Strahler, A. H., 1993, An analytic BRDF model of canopy radiative transfer and its inversion. IEEE Transactions on Geoscience and Remote Sensing, 31, 1081-1092.

LiAng, S., and STRAHLER, A. H., 1994. Retrieval of surface BRDF from multiangle remotely sensed data. Remote Sensing of Environment, 50, 18-30.

LiANG, S., and STRAHLER, A. H., 1995, An analytic radiative transfer model for a coupled atmosphere and leaf canopy. Journal of Geophysical Research, 100, 5085-5094.

LiAnG, S., and TownSHEND, J. R. G., 1997, Angular signatures of NOAA/NASA Pathfinder AVHRR Land data and applicationsto land cover identification. International Geoscience and Remote Sensing Symposium, Singapore, 3-8 August 1997 (Piscalaway, NJ: IEEE), pp. 1781-1783.

Menenti, M., AzZali, S., Verhoef, W., and van Swol, R., 1993, Mapping agroecological zones and time lag in vegetation growth by means of Fourier analysis of time series of NDVI images. Advances in Space Research, 13, 233-237.

Minnaert, M., 1941, The reciprocity principle in lunar photometry. Astrophysical Journal, 93, 403-410.

Myneni, R. B., Asrar, G., and Hall, F. G., 1992, A three dimensional radiative transfer model for optical remote sensing of vegetated land surfaces. Remote Sensing of Environment, 41, 85-103. 
Myneni, R. B., Maggion, S., Iaquinta, J., Privette, J. L., Gobron, N., Pinty, B., Kimes, D. S., Verstraete, M. M., and Williams, D. L., 1995, Optical remote sensing of Vegetation: modeling, caveats, and algorithms. Remote Sensing of Environment, 51, 169-188.

Nicodemus, F. E., Richmond, J. C., HsiA, J. J., GinsBerG, I. W., and Limperis, T., 1977, Geometrical considerations and nomenclature for reflectance. NBS Monograph 160, National Bureau of Standards, Washington DC.

Nilson, T., and KUUSK, A., 1989, A reflectance model for homogeneous plant canopies and its inversion. Remote Sensing of Environment, 27, 157-167.

O’Neill, N. T., Zagolski, F., Bergeron, M., Royer, A., Miller, J. R., and Freemantle, J., 1997, Atmospheric correction validation of casi images acquired over the Boreas southern study area. Canadian Journal of Remote Sensing, 23, 143-162.

PINKER, R. T., and LASZLO, I., 1990, Improved prospects for estimating insolation for calculating regional evapotranspiration from remotely sensed data. Agricultural and Forest Meteorology, 52, 227-251.

Powell, M. J. D., 1964, An efficient method for finding the minimum of a function of several variables without calculating derivatives. Computer Journal, 7, 155-162.

Privette, J. L., EcK, T. F., and Deering, D. W., 1997, Estimating spectral albedo and nadir reflectance through inversion of simple BRDF models with AVHRR/MODIS-like data. Journal of Geophysical Research, 102, 29529-29542.

PrivetTe, J. L., EMERY, W. J., and SCHIMEL, D. S., 1996, Inversion of a vegetation reflectance model with NOAA AVHRR data. Remote Sensing of Environment, 58, 187-200.

Rahman, H., Pinty, B., and Verstraete, M. M., 1993a, Coupled surface-atmospheric reflectance (CSAR) model. 2. Semiempirical surface model usable with NOAA Advanced Very High Resolution Radiometer. Journal of Geophysical Research, 98, 20791-20 801.

Rahman, H., Verstraete, M. M., and Pinty, B., 1993b, Coupled surface-atmosphere reflectance model (CSAR). 1. Model description and inversion against synthetic data. Journal of Geophysical Research, 98, 20779-20789.

Ranson, K. J., IRONS, J. R., and DAughtry, C. S. T., 1991, Surface hemispherical reflectance from bidirectional reflectance. Remote Sensing of Environment, 35, 201-211.

Roujean, J. L., LATOY, M., and Deschamps, P. Y., 1992, A bidirectional reflectance model of the earth's surface for the correction of remote sensing data. Journal of Geophysical Research, 97, 20 455-20468.

Russell, C. A., Walthall, C. L., Irons, J. R., and Brown de Colstoun, E. C., 1995, Comparison of airborne and surface spectral bidirectional reflectance factors, spectral hemispherical reflectance and spectral vegetation indices. Journal of Geophysical Research, 100, $25509-25522$.

SMith, P. M., and KalluRI, S. N. V., 1997, Corrections to and status of the Pathfinder NOAA/ NASA AVHRR 8-km land data set. EOS, Transactions, American Geophysical Union, 78, S79.

Stowe, L. L., McClain, E. P., Carey, R., Pellegrino, P., Gutman, G. G., Davis, P., Long, C., and HART, S., 1991, Global distribution of cloud cover derived from NOAA/AVHRR operational satellite data. Advances in Space Research, 3, 51-54.

Strahler, A. H., Lucht, W., SchaAf, C. B., Tsang, T., Gao, F., Li, X., Muller, J. P., Lewis, P., and BARnSLEY, M. J., 1999, MODIS BRDF/Albedo Product: Algorithm Theoretical Basis Document (Version 5), URL : http://modarch.gsfc.nasa.gov/

Verhoef, W., Menenti, M., and AzZali, S., 1996, A colour composite of NOAA-AVHRR-NDVI based on time series analysis (1981-1992). International Journal of Remote Sensing, 17, 231-235.

Verstraete, M. M., and Flasse, S., 1996, Recent advances in algorithm development to extract information from AVHRR data. In Recent Advances in Algorithm Development to Extract Information from AVHRR Data, edited by G. D'Souza, A. S. Belward and J. P. Malingreau (London: Kluwer Academic), pp.211-229.

Walthall, C. L., 1997, A study of reflectance anisotropy and canopy structure. Remote Sensing of Environment, 61, 118-128.

Walthall, C. L., Norman, J. M., Welles, J. W., Campbell, G., and Blad, B. L., 1985, Simple equation to approximate the bidirectional reflectance from vegetated canopies and bare soil surfaces. Applied Optics, 24, 383-387.

Zhang, Z., Kalluri, S., JÁJÁ, J., Liang, S., and Townshend, J. R. G., 1998, High performance algorithms for global BRDF retrieval. IEEE Transactions on Computational Science and Engineering, 5, 16-29. 